\title{
Las condiciones eximentes de responsabilidad administrativa en el Texto Unico Ordenado de la Ley del Procedimiento Administrativo General y su incidencia en la legislación ambiental \\ Exemption conditions of liability in the Law on General Administrative Procedure and its incidence in the environmental legislation
}

\section{CÉSAR ABRAHAM NEYRA CRUZADO* \\ Organismo de Evaluación y Fiscalización Ambiental}

Resumen: con ocasión de las modificaciones legislativas contenidas en el Texto Único Ordenado de la ley 27444, Ley del Procedimiento Administrativo General, se analiza la naturaleza jurídica de los novísimos eximentes de responsabilidad administrativa. Asimismo, se hace un recuento de los eximentes que ya existían en la legislación ambiental y cómo venían operando. Finalmente, se establece los puntos de contacto entre un régimen de responsabilidad subjetiva, basado en la culpabilidad, y un sistema de responsabilidad objetiva relativa, basado en el riesgo.

Palabras clave: eximentes de responsabilidad, responsabilidad objetiva, responsabilidad subjetiva, subsanación voluntaria, caso fortuito, fuerza mayor, hecho determinante de tercero, fiscalización ambiental

\begin{abstract}
: on the occasion of the recent legislative changes contained in the Ordered Text of law 27444, Law on General Administrative Procedure, the legal nature of the most recent exemptions of administrative liability is analyzed. Likewise, a count is made of the exemptions that already existed in the environmental legislation and how they had been operating; in order to see the points of contact between a subjective liability regime, based on guilt, and a relative, risk-based objective liability system.
\end{abstract}

Key words: exemptions of responsibility, objective responsibility, subjective responsibility, voluntary correction, administrative sanctioning procedure, environmental protection

CONTENIDO: I. INTRODUCCIÓN.- II. DERECHO ADMINISTRATIVO SANCIONADOR GENERAL.- II.1. EXIMENTES DE RESPONSABILIDAD.- II.1.1. CASO FORTUITO Y FUERZA MAYOR.- II.1.2. CUMPLIMIENTO DE UN DEBER LEGAL Y LEGÍTIMA DEFENSA.- II.1.3. INCAPACIDAD MENTAL.- II.1.4. ORDEN

* Presidente del Tribunal de Fiscalización Ambiental del Organismo de Evaluación y Fiscalización Ambiental. Abogado y Magíster en Derecho de la Empresa por la Pontificia Universidad Católica del Perú. Actualmente sigue estudios de Doctorado en Derecho y Ciencia Política en la Universidad Nacional Mayor de San Marcos.

Código ORCID: 0000-0002-3544-8687. Correos electrónicos: cneyra@oefa.gob.pe y neyra.ca@ pucp.edu.pe 
OBLIGATORIA DE AUTORIDAD COMPETENTE.- II.1.5. EL ERROR INDUCIDO POR LA ADMINISTRACIÓN.- II.1.6. LA SUBSANACIÓN VOLUNTARIA.II.2. CONFIGURACIÓN DE LOS EXIMENTES.- III. DERECHO ADMINISTRATIVO SANCIONADOR AMBIENTAL.- III.1. SISTEMA DE RESPONSABILIDAD OBJETIVA RELATIVA.- III.2. MEDIDAS DE MITIGACIÓN O REMEDIACIÓN.III.3. PERSECUCIÓN DEL DAÑO Y DEL RIESGO.- III.4. EXIMENTES DE RESPONSABILIDAD.- III.4.1. SUBSANACIÓN VOLUNTARIA.- III.4.2. CASO FORTUITO Y FUERZA MAYOR.- III.5. LA CARGA DE LA PRUEBA DE LOS EXIMENTES EN MATERIA AMBIENTAL.- IV. CONCLUSIONES.

\section{INTRODUCCIÓN}

La Ley del Procedimiento Administrativo General (27444) fue publicada el 11 de abril de 2001, estableciendo y consolidando las principales instituciones que debían regular el derecho administrativo peruano. Durante su vigencia, ha sido modificada en varias ocasiones. Destacan las modificaciones realizadas por el decreto legislativo 1029, publicado el 24 de junio de 2008, así como las modificaciones introducidas por el decreto legislativo 1272, publicado el 21 de diciembre de 2016. Todo lo cual ha sido sistematizado y compilado en el Texto Único Ordenado aprobado por decreto supremo 006-2017-JUS, publicado el 20 de marzo de 2017 (en adelante TUO de la LPAG).

En el artículo II del Título Preliminar del TUO de la LPAG se señala que dicha norma contiene las normas comunes, esto es las normas mínimas, que se debe seguir en todas las actuaciones de la función administrativa del Estado, incluyendo los procedimientos especiales. Esto implica un cambio importante pues anteriormente las normas administrativas generales operaban supletoriamente, esto es, cuando existía un vacío en las normas que regulaban los procedimientos especiales.

Adicionalmente, en el marco de la responsabilidad administrativa subjetiva se ha introducido en el artículo 255 del TUO de la LPAG seis causales eximentes de responsabilidad administrativa. Estas causales eximentes permiten al infractor verse liberado de la sanción aplicable aun cuando haya cometido una infracción administrativa.

Por otro lado, la Ley General del Ambiente y la Ley del Sistema Nacional de Evaluación y Fiscalización Ambiental, entre otras normas sectoriales, parten de supuestos distintos. Uno de ellos es que la responsabilidad administrativa es de naturaleza objetiva. Otro, no menos importante, es que los daños o riesgos generados como parte de una actividad económica deben ser mitigados por el administrado, más allá de que sea aplicable una sanción o no.

En tal sentido, resulta necesario considerar cómo interactúan entre sí y cómo conciliamos este derecho administrativo sancionador general 
— contenido en el TUO de la LPAG - que aspira a brindar normas comunes a toda actuación estatal con el derecho administrativo sancionador especial-ambiental —desarrollado en la Ley General del Ambiente y sus normas complementarias y conexas-, que por su propia naturaleza es trasversal a todo el ordenamiento jurídico.

\section{DERECHO ADMINISTRATIVO SANCIONADOR GENERAL}

El artículo 246 del TUO de la LPAG ha establecido once principios que rigen la potestad sancionadora de todas las entidades públicas: legalidad, debido procedimiento, razonabilidad, tipicidad; irretroactividad, concurso de infracciones, continuación de infracciones, causalidad, presunción de licitud, culpabilidad y non bis in idem. Estos principios cumplen una triple función: «la fundante (preceder a la existencia de las reglas mismas de la potestad sancionadora), la interpretativa (servir de criterio hermenéutico para absolver cualquier duda sobre el sentido y alcance de las reglas de la potestad sancionadora), y la integradora (servir de fuente de integración para las lagunas jurídicas que se puedan identificar en la aplicación de las normas sancionadoras)» (Morón, 2014, p. 748).

Una novedad importante del TUO de la LPAG es que encontramos expresamente consagrado al principio de culpabilidad que establece que «La responsabilidad administrativa es subjetiva, salvo los casos en que por ley o decreto legislativo se disponga la responsabilidad administrativa objetiva ${ }^{1}$ ». Antes de dicha incorporación, se infería — sobre la base de dos expresiones contenidas en la Ley del Procedimiento Administrativo General: «intencionalidad de la conducta» y «quien realiza la conducta»; así como de la jurisprudencia del Tribunal Constitucional- que, en el derecho administrativo sancionador peruano, la regla general era que para poder sancionar se requería culpabilidad. La culpabilidad era entonces entendida no solo como responsabilidad por el hecho, sino también como exigencia de dolo o de culpa. Además, se seguía excepcionalmente, que solo sería posible sancionar objetivamente en el ámbito administrativo cuando se esté ante infracciones sancionadas por «peligro hipotético», que penalmente no podrían ser castigadas (Baca, 2010, p. 15).

1 Como se puede apreciar, el legislador ha creado un régimen general (sistema de responsabilidad subjetiva) y un régimen especial (sistema de responsabilidad objetiva), teniendo como punto de contacto ambos sistemas el hecho de que la administración deberá acreditar el nexo causal entre el sujeto y la conducta infractora. Claro está que en el régimen especial bastará que se acredite el nexo causal para declarar la existencia de responsabilidad administrativa. En cambio, en el régimen general, adicionalmente, se deberá acreditar que el sujeto actuó con dolo o culpa (Ministerio de Justicia, 2017, p. 29)—. 
Por otro lado, como premisa general, se debe tener presente que mientras que, por un lado, al derecho penal le corresponde «la función de restablecer normativamente la norma defraudada por la conducta del infractor»; en cambio, la finalidad que cumple el derecho administrativo sancionador (DAS) es «el mantenimiento del funcionamiento global del sector social administrativamente regulado» (García Cavero, 2012, p. 140). En tal sentido, en el DAS general se sancionarán aquellas conductas culpables que impidan el normal funcionamiento de un sector regulado. Sin embargo, se permite que el infractor sea liberado de la sanción cuando concurran circunstancias eximentes de responsabilidad.

\section{II.1. Eximentes de responsabilidad}

Como una primera aproximación, el Diccionario de la Lengua Española nos dice que «eximir» significa «librar, desembarazar de cargas, obligaciones, cuidados, culpas, etcétera» y que una «circunstancia eximente» representa un «motivo legal para librar de responsabilidad criminal al acusado». Como se puede apreciar, desde el punto de vista semántico hay dos circunstancias bien definidas: primero, una persona tiene una obligación que cumplir o asumir; segundo, por una razón especial, esta misma persona es liberada de su obligación.

Ya en su configuración legal, el artículo 255 del TUO de la LPAG ha introducido seis causales de eximencia de responsabilidad, conforme se puede apreciar a continuación:

\section{Cuadro 1}

\begin{tabular}{|c|c|}
\hline Versión anterior & Versión actual \\
\hline $\begin{array}{l}\text { Artículo [236-A].- Atenuan- } \\
\text { tes de Responsabilidad por } \\
\text { Infracciones } \\
\text { Constituyen condiciones ate- } \\
\text { nuantes de la responsabilidad: } \\
\text { 1.- La subsanación voluntaria } \\
\text { antes de la notificación de } \\
\text { la imputación de cargos. } \\
\text { 2.- Error inducido por la ad- } \\
\text { ministración por un acto } \\
\text { o disposición administra- } \\
\text { tiva, confusa o ilegal. }\end{array}$ & $\begin{array}{l}\text { Artículo 255.- Eximentes y atenuantes de responsabilidad por } \\
\text { infracciones } \\
\text { 1.- Constituyen condiciones eximentes de la responsabilidad } \\
\text { por infracciones las siguientes: } \\
\text { a. El caso fortuito o la fuerza mayor. } \\
\text { b. Obrar en cumplimiento de un deber legal o el ejercicio } \\
\text { legítimo del derecho de defensa. } \\
\text { c. La incapacidad mental debidamente comprobada. } \\
\text { d. La orden obligatoria de autoridad competente. } \\
\text { e. El error inducido por la administración o por disposi- } \\
\text { ción administrativa confusa o ilegal. } \\
\text { f. La subsanación voluntaria con anterioridad a la notifi- } \\
\text { cación de la imputación de cargos. } \\
\text { 2.- Constituyen condiciones atenuantes de la responsabilidad } \\
\text { por infracciones las siguientes: } \\
\text { a. Si iniciado un procedimiento administrativo sanciona- } \\
\text { dor el infractor reconoce su responsabilidad de forma } \\
\text { expresa y por escrito; con lo que se reduce la multa. } \\
\text { b. Otros que se establezcan por norma especial. }\end{array}$ \\
\hline
\end{tabular}

Fuente: elaboración propia sobre la base de la versión original de la LPAG (ley 27444) y actual TUO de la LPAG. 
Así, en su versión anterior, la Ley del Procedimiento Administrativo General contenía únicamente dos condiciones atenuantes de responsabilidad: 1) la subsanación voluntaria y 2) el error inducido por la administración. Por ello, se señalaba que, cuando se producían dichas circunstancias, no se afectaba la comisión de la infracción administrativa, por cuanto esta no desaparece, sino que únicamente se afectaba la cuantía de la pena a aplicarse. Asimismo, se citaba como ejemplo de subsanación voluntaria el hecho de que el administrado obtenga su licencia después de haber iniciado sus actividades sin título habilitante. Para el caso de error inducido, se citaba la circunstancia que se produce cuando la administración emite normas ilegales (Morón, 2014, p. 809).

Sin embargo, en su configuración actual, el TUO de la LPAG ha mutado dichas circunstancias de atenuantes a eximentes de responsabilidad administrativa. A la vez, ha introducido cuatro nuevos supuestos: 3) el caso fortuito y fuerza mayor; 4) obrar en cumplimiento de un deber legal y la legítima defensa; 5) la incapacidad mental debidamente comprobada; y 6) la orden obligatoria de autoridad competente. Veamos las características principales de cada uno de ellos.

\section{II.1.1. Caso fortuito y fuerza mayor}

El artículo 255 (1.a) señala que constituye condición eximente «El caso fortuito o la fuerza mayor debidamente comprobada». Como se sabe, estas son circunstancias eximentes que están contempladas desde hace mucho tiempo atrás en la legislación civil y penal.

Conforme a diversas tradiciones jurídicas, al caso fortuito también se lo ha denominado «hechos de la naturaleza» o «actos de dios» y a la fuerza mayor, «procederes de la autoridad» o «hechos del príncipe». Por ello, se señala que el caso fortuito y la fuerza mayor, desde el punto de vista objetivo, son acontecimientos extraordinarios, imprevisibles e inevitables. Desde el punto de vista subjetivo, se trata de un hecho en el que hay ausencia de voluntad directa o indirecta, es decir, no hay autoría moral (Vidal Ramos, 2014, p. 142).

\section{II.1.2. Cumplimiento de un deber legal y legítima defensa}

El artículo 255 (1.b) establece que constituye condición eximente «obrar en cumplimiento de un deber legal o el ejercicio legítimo del derecho de defensa». Como se sabe, por regla general toda conducta típica es antijurídica. Sin embargo, en algunos casos especiales no se cumplirá esta situación, pues, por un lado, el ordenamiento jurídico prohíbe una conducta determinada, pero, por otro lado, la permite.

Es decir, existe una aparente contradicción al interior del ordenamiento jurídico. Por ejemplo, yo tengo derecho a la libertad de tránsito, pero un policía tiene la obligación de detenerme cuando le ha sido entregada 
una orden del juez a ese efecto. En estos casos se está frente a un conflicto entre dos bienes jurídicos, por lo que el operador debe salvar el preponderante para el derecho positivo (Rodríguez Hurtado, Ugaz Zegarra, Gamero Calero \& Schönbohm, 2012, p. 78).

De igual forma, cuando en cumplimiento de un deber legal, una ambulancia vulnera las reglas de tránsito para salvar la vida del paciente o cuando la policía infringe las normas de seguridad vial para perseguir y detener a un delincuente en fuga, se está ante una conducta típica, pero no antijurídica, por lo que no cabe un reproche por parte de la administración (Gómez \& Sanz, 2010, p. 450).

Encontramos un caso similar en la legislación financiera. Por un lado, un funcionario bancario tiene el deber de guardar reserva sobre las operaciones que realizan sus clientes, pero, por otro lado, si tiene sospechas sobre la legalidad de las transacciones, tiene la obligación legal de reportarlas ante la autoridad competente. Por lo que el cliente-infractor no puede acusarlo de haber vulnerado su secreto bancario y a su vez el funcionario no es pasible de sanción administrativa o penal.

Finalmente, es conocido que «La legítima defensa es el caso más unívoco y tangible de causal de justificación. Aquí se puede reconocer notoriamente al ilícito agresor frente al derecho defendido [...] básicamente la legítima defensa no depende de una ponderación de intereses en disputa, la defensa se determina según la peligrosidad e intensidad de la agresión y no de acuerdo al valor del bien atacado» (Rodríguez Hurtado, Ugaz Zegarra, Gamero Calero \& Schönbohm, 2012, p. 80). Es decir, existe una habilitación legal para lesionar al agresor.

\section{II.1.3. Incapacidad mental}

El artículo 255 (1.c) establece que constituye condición eximente «la incapacidad mental debidamente comprobada por la autoridad competente, siempre que esta afecte la aptitud para entender la infracción». Tal como hemos señalado anteriormente, una infracción administrativa se produce cuando la acción es típica, antijurídica y culpable. En este contexto, la culpabilidad está referida a que debe evaluarse si el administrado tiene la capacidad para responder jurídicamente por sus acciones. Es decir, será imputable en la medida que esté en pleno uso de sus facultades físicas y mentales, y que estas le permitan percibir adecuadamente la realidad.

Nótese que en esta etapa no se evalúa el grado de intencionalidad del administrado cuando desarrolló el tipo subjetivo de la infracción, sino el supuesto subyacente en dicha conducta: que no existía una circunstancia que lo incapacite mentalmente para evaluar sus propios 
actos. Por supuesto, ambos niveles de análisis están estrechamente vinculados y se condicionan mutuamente. Sin embargo, son separados por motivos metodológicos (García Cavero, 2012, p. 635).

\section{II.1.4. Orden obligatoria de autoridad competente}

El artículo 255 (1.d) establece que constituye condición eximente «la orden obligatoria de autoridad competente, expedida en ejercicio de sus funciones». En dicha circunstancia también encontramos un conflicto normativo por la contraposición de dos bienes jurídicos protegidos. Nuevamente estamos en un supuesto en que la acción es típica pero no antijurídica.

Cabe anotar que la ejecución de una orden obligatoria de autoridad competente, para que sea un eximente de responsabilidad administrativa, debe tener una apariencia de legitimidad, es decir, no debe ser groseramente ilegal. Muñoz Conde señala, entre otros, como presupuestos que determinan la actuación del administrado los requisitos siguientes: 1) competencia del subordinado para ejecutar el acto ordenado por el superior; y 2) que la orden sea expresa y que aparezca revestida de las formalidades legales necesarias (Rodríguez Hurtado, Ugaz Zegarra, Gamero Calero \& Schönbohm, 2012, p. 84).

El Tribunal Constitucional peruano se ha pronunciado sobre la obediencia debida señalando lo siguiente:

no cabe aceptar la existencia de deberes que resulten manifiestamente contrarios a los derechos fundamentales o, en general, a los fines constitucionalmente legítimos perseguidos por el ordenamiento jurídico. Por consiguiente, tanto quien exige el cumplimiento de una orden ilícita, como quien la acata, quebrantan el ordenamiento jurídico, en mayor o menor gravedad, y en proporción directa a la relevancia del bien jurídico mellado a consecuencia de la ejecución del acto (Efraín Raúl Chambilla Figueroa c. Director General de Personal de la PNP, fundamento 10).

Un requisito adicional, en el ámbito del sistema nacional de control, consiste en que el administrado se haya opuesto por escrito a la orden recibida que luego habrá de ejecutar. Solo cumpliendo dicha formalidad, salvará su responsabilidad administrativa (Decreto supremo 023-2011PCM, artículo 18).

\section{II.1.5. El error inducido por la administración}

El artículo 255 (1.e) establece que constituye condición eximente «el error inducido por la Administración o por disposición administrativa confusa o ilegal». Esto es así debido a que, en virtud del principio de predictibilidad o confianza legítima contemplado en el Título Preliminar del TUO de la LPAG, la autoridad administrativa tiene la obligación de brindar a los administrados información veraz, completa y confiable

LAS CONDICIONES

EXIMENTES DE

RESPONSABILIDAD

ADMINISTRATIVA

EN EL TEXTO

ÚNICO ORDENADO

DE LA LEY DEL

PROCEDIMIENTO

ADMINISTRATIVO

GENERAL Y SU

INCIDENCIA EN

LA LEGISLACIÓN

AMBIENTAL

EXEMPTION

CONDITIONS OF

LIABILITY INTHE

LAW ON GENERAL

ADMINISTRATIVE

PROCEDURE

AND ITS

INCIDENCE IN THE ENVIRONMENTAL

LEGISLATION 
sobre los procedimientos a su cargo. Esto, a su vez, permitirá que los administrados se formen una idea adecuada de los procedimientos y requisitos que deben cumplir para ver satisfechas sus expectativas.

Pues bien, en el error inducido por la administración, se da la vulneración manifiesta del citado principio. Este «mal consejo» genera, como consecuencia principal, que la autoridad administrativa no podrá sancionar al administrado y, como consecuencia secundaria, al interior de la propia administración, que se tenga que determinar la responsabilidad del funcionario que emitió dicho acto.

Un supuesto de error inducido por la administración se produce cuando esta «aconseja» a los presuntos infractores para que actúen de determinada manera y luego les impone una multa. Por ello, es correcto que el Poder Judicial revoque la multa impuesta al considerar que los sancionados obraron en la legítima confianza que actuaban, ya que sería absurdo sancionar una conducta que la propia administración aconsejaba (Nieto, 2012, p. 411).

Por otro lado, el Tribunal Superior de Responsabilidad Administrativa de la Contraloría General de la República ha señalado que «cabe resaltar la trascendencia que tiene para el Derecho Administrativo Sancionador que el infractor sea un profesional o un lego, toda vez que cuando la infracción es cometida en el ejercicio de una profesión o actividad especializada "se esfuma la posibilidad de error porque — por así decirlo— la norma ha impuesto la obligación de no equivocarse y opera, en consecuencia, la presunción de que no se ha equivocado"» (Resolución 004-2013-CG/TSRA, fundamento 4.15; citando a Nieto).

En esa misma línea jurisprudencial, cuando un gobierno local aprobó el presupuesto institucional de apertura (PIA 2011) vulnerando las normas del sistema nacional de presupuesto público, el Tribunal Superior de Responsabilidad Administrativa señaló que la administrada, en su calidad de jefe de planeamiento y presupuesto, debió dar cumplimiento a las leyes vigentes y no a los actos administrativos emitidos por el concejo municipal (Resolución 027-2014-CG/TSRA, fundamento 5.42). Por ello, su conducta no estaba incursa en una causal eximente.

Como se pude apreciar, el nivel de exigencia para superar casos de error inducido por la administración varía conforme a las calidades personales de los administrados. Por un lado, si un administrado es un lego en derecho, el grado de exigencia para superar el error es menor, por lo que es muy posible que opere la causal eximente. Por otro lado, si estamos ante un funcionario público que tiene la obligación legal de custodiar fondos públicos o recursos naturales, será muy difícil que opere la causal eximente, pues, en el fondo, será su propio error de juicio el que lo llevó a cometer la infracción administrativa. 


\section{II.1.6. La subsanación voluntaria}

El artículo 255 (1.f) establece que constituye condición eximente «la subsanación voluntaria por parte del posible sancionado del acto u omisión imputado como constitutivo de infracción administrativa, con anterioridad a la notificación de la imputación de cargos...». Dicho precepto parte de la premisa de que existen obligaciones subsanables, pero no nos dice cuáles son y tampoco nos indica qué obligaciones son insubsanables.

Para formarnos una idea de esta dicotomía entre obligaciones subsanables y no subsanables, veamos un antecedente judicial. A través de un Acuerdo Plenario (2-2009/CJ-116), la Corte Suprema de Justicia interpretó los alcances de la subsanación voluntaria contenida en el artículo 189 del Código Tributario, señalando que el posible infractor penal-tributario únicamente se verá libre de responsabilidad si 1) antes de ser detectado por la administración declara lo que realmente debe y, no menos importante, 2) paga el íntegro de la deuda. Es decir, la regularización o subsanación debe ser voluntaria: «Esta exigencia o condicionante temporal plantea que la regularización se realice en forma voluntaria o espontánea, la que debe concretarse antes de la intervención de la autoridad tributaria o penal» (Acuerdo Plenario 2-2009/CJ-116, fundamento II, numeral 11, A).Con respecto al pago total de la deuda tributaria, «[n] o solo se trata de que se formule una autodenuncia a través de una declaración rectificatoria, sino de que pague efectivamente la deuda tributaria» (Acuerdo Plenario 2-2009/ CJ-116, fundamento II, numeral 11, B).

Por otro lado, también es posible observar esta dicotomía entre obligaciones subsanables y no subsanables en una norma sectorial correspondiente al Organismo Supervisor de la Inversión Privada el Telecomunicaciones (Resolución 056-2017-CD-OSIPTEL). En dicha normal, se precisa que operará la subsanación voluntaria siempre que se verifique que la infracción ha cesado y que se han revertido los efectos negativos de la misma. Es decir, si los efectos negativos de la conducta no se pueden revertir, por definición, no puede haber subsanación de la conducta.

Finalmente, consideramos que la «oportunidad» de la subsanación voluntaria pudo haber sido regulada de otra manera, brindando mayores incentivos para el debido cumplimiento de las normas administrativas. Advirtamos que, si dividimos hipotéticamente la operatividad de la subsanación voluntaria en tres segmentos, obtenemos lo siguiente.

- Primer tramo: entre la comisión de la infracción y la detección por parte de la autoridad 
- Segundo tramo: entre la detección de la infracción y el inicio del procedimiento administrativo sancionador (PAS)

- Tercer tramo: inicio del PAS y la resolución que impone la sanción

Pues bien, hubiera sido deseable que el legislador premie al posible infractor si realiza la subsanación en el primer tramo, liberándolo del $100 \%$ de la multa; disminuya la multa al 50\% cuando el infractor ha sido detectado y, por ello, subsana en el segundo tramo; y finalmente, la multa disminuya solo en $25 \%$ cuando la subsanación se realiza en el tercer tramo. De esta forma, se pondría en evidencia ante la ciudadanía que lo que se busca con las acciones de fiscalización es el estricto cumplimiento de la norma y la reversión en el plazo más corto de los efectos negativos que se hubieran podido generar.

Contrariamente a lo antes expuesto, el artículo 255 (1.f) deja de lado el primer y tercer tramo, concentrando sus efectos únicamente en el segundo tramo, esto es cuando la infracción ya ha sido detectada por la Administración. De este modo se genera un incentivo perverso para que el infractor cumpla con la norma únicamente cuando es descubierto.

\section{II.2. Configuración de los eximentes}

Ahora bien, estos eximente de responsabilidad administrativa operan ante la ausencia de tipicidad, antijuricidad o culpabilidad en la conducta del presunto infractor. Veámoslos con mayor detalle.

Tipicidad: El caso fortuito y la fuerza mayor cuestionan la tipicidad de la conducta, pues el administrado no puede resistir dichas circunstancias ni tampoco su voluntad tiene incidencia en el desarrollo de los hechos. Asimismo, el error inducido por la administración cuestiona la tipicidad subjetiva de la norma, pues, en un primer momento, el Estado emite una norma y exige su debido cumplimiento. Sin embargo, en un segundo momento, la Administración le indica al presunto infractor que está fuera del supuesto de la norma. Por eso, este «consejo» de la administración produce un error de tipo subjetivo en el administrado, quien cree erróneamente que su actuar se ajusta a derecho.

Antijuricidad ${ }^{2}$ : Consiste en obrar en cumplimiento de un deber legal y la legítima defensa. Así como en el caso de la orden obligatoria de autoridad competente, cuestionan la antijuridicidad, pues, si bien el

2 En España se señala, sobre la antijuricidad, que "la traslación de esta exigencia al ámbito administrativo sancionador ha resultado especialmente compleja, pues no se recoge en norma administrativa alguna y, en el propio ámbito penal, su consagración tampoco se produce claramente por vía normativa" (Rebollo Puig \& et al., 2010, p. 221). Esto también es cierto en el caso peruano, pues la antijuricidad no la encontramos expresamente contemplada en el TUO de la LPAG, pero se trata de la otra cara que junto con la tipicidad forman una misma moneda. Por ello, la antijuricidad explica muy bien cuál es el fundamento de ciertos eximentes de responsabilidad. 
administrado desarrolla la conducta típica descrita en una norma, tiene a su favor otra norma que justifica su actuación. Asimismo, en la subsanación voluntaria, en un primer momento se da la conducta típica, antijurídica y culpable, es decir, se vulnera un bien jurídico protegido. Sin embargo, en un segundo momento, al ser enmendada la conducta y revertir sus efectos antes de la imputación de cargos, se restituye la vigencia del bien jurídico protegido. Bien visto, el propio ordenamiento jurídico le permite al administrado «corregir» su conducta.

Culpabilidad: La incapacidad mental debidamente comprobada cuestiona la culpabilidad del administrado, pues, bajo determinadas circunstancias, este resulta inimputable.

Como se puede apreciar, los eximentes de responsabilidad administrativa actúan de diversa manera. Un primer grupo ataca la tipicidad; un segundo grupo, la antijuricidad; y un tercer grupo, la culpabilidad. La consecuencia de ello es que la ausencia de uno de estos elementos hará que no se llegue a configurar la infracción administrativa. Es decir, en estos casos estaremos ante un presunto infractor al que no cabe sancionar.

Sin perjuicio de lo antes expuesto, desde las normas del sistema nacional de control, se señala que la «configuración del eximente no afecta la tipicidad del hecho imputado, sino únicamente su antijuridicidad y consiguiente merecimiento de sanción en el caso concreto» (Reglamento de infracciones y sanciones, art. 18; el cual ha sido desarrollado por el Procedimiento Administrativo Sancionador por Responsabilidad Administrativa Funcional (directiva 010-2016-CG/GPROD), numeral 7.2.22). Si bien, no compartimos el sentido general de esta declaración, reconocemos que tiene idéntico resultado: el presunto infractor se libra de la sanción.

\section{DERECHO ADMINISTRATIVO SANCIONADOR AMBIENTAL}

El numeral 22 del artículo 2 de la Constitución establece como derecho humano fundamental el gozar de un ambiente equilibrado y adecuado al desarrollo de su vida. Además, conforme al artículo 44 del citado texto, el Estado tiene el deber de garantizar la plena vigencia de los derechos humanos. Por lo tanto, se encuentra en la obligación de hallar el equilibrio entre el desarrollo económico y la protección ambiental, determinando cuáles son los riesgos permitidos y sancionando la comisión de los riesgos no permitidos.

Para lograr estos cometidos, el derecho ambiental interviene en tres dimensiones fundamentales: «una es la de control ambiental, otra es de la intervención sancionatoria y a ellas se añade, recientemente, una tercera 
línea de intervención orientada a conseguir la reparación de los daños causados al medio ambiente» (Esteve Pardo, 2014, p. 46).

En ese sentido, adelantamos que, si bien al operar los eximentes de responsabilidad el administrado se libera de la sanción, ello no impide que se le exija que repare los daños causados al ambiente durante el desarrollo de su actividad. Solo de esta forma 1) el Estado garantiza a la ciudadanía que pueda gozar de un ambiente equilibrado y adecuado para el desarrollo de la vida y 2) se preserva el ambiente para las generaciones futuras. Es decir, de este modo se dota de contenido al mandato constitucional. Esto es así en función de los presupuestos de los que parte el DAS ambiental y que a continuación desarrollamos.

\section{III.1. Sistema de responsabilidad objetiva relativa}

El artículo 144 de la Ley General del Ambiente crea un régimen de responsabilidad objetiva: «La responsabilidad derivada del uso o aprovechamiento de un bien ambientalmente riesgoso o peligroso, o del ejercicio de una actividad ambientalmente riesgosa o peligrosa, es objetiva». De esta manera, la responsabilidad objetiva está reservada para daños ocasionados por el ejercicio de una actividad riesgosa. En última instancia, este es el fundamento de que el administrado asuma los costos de la reparación del daño ambiental generado por su actividad, aún en el supuesto de que haya actuado sin infringir la regulación sectorial.

Sin perjuicio de lo anterior, el artículo 146 de la Ley General del Ambiente ha establecido las siguientes causas eximentes de responsabilidad:

a) Cuando concurran una acción u omisión dolosa de la persona que hubiera sufrido un daño resarcible de acuerdo con esta ley;

b) Cuando el daño o el deterioro del medio ambiente tenga su causa exclusiva en un suceso inevitable o irresistible; y,

c) Cuando el daño o el deterioro del medio ambiente haya sido causado por una acción y omisión no contraria a la normativa aplicable, que haya tenido lugar con el previo consentimiento del perjudicado...».

Por ello, realmente estamos frente a un régimen de responsabilidad objetiva relativa que contempla como causales eximentes de responsabilidad el hecho determinante de un tercero o caso fortuito o fuerza mayor. De darse estos eximentes, no existe responsabilidad administrativa y, por tanto, en dichas circunstancias no cabe que se le impongan sanciones pecuniarias al administrado. Esto no implica, sin embargo, que no continúe obligado a reparar el daño generado por su actividad, es decir, que reponga las cosas al estado anterior. 
Es así que «quien realiza actividades como el transporte de residuos sólidos peligrosos es responsable de los daños ambientales que ocasione como consecuencia de tal actividad, sin necesidad de que exista dolo o culpa». Por ello, «quien es hallado responsable por la comisión de un daño ambiental deberá [...] asumir los costos que se deriven de las medidas de prevención y mitigación de daño, así como los costos relativos a la vigilancia y monitoreo de la actividad y de las medidas de prevención y mitigación adoptadas» (Puente $\&$ Vargas, 2015, p. 105).

Finalmente, a mayor abundamiento, es preciso señalar que la regulación peruana de la responsabilidad objetiva relativa guarda semejanza con el sistema europeo de responsabilidad objetiva. Pues en el Libro Blanco sobre responsabilidad ambiental expresamente se señala que en un régimen de responsabilidad objetiva también deberán admitirse las circunstancias eximentes y atenuantes habitualmente aceptadas, como en los casos de fuerza mayor o de intervención de un tercero (Comunidad Europea, 2000).

A mayor detalle, la directiva Sobre responsabilidad medioambiental en relación con la prevención y reparación de daños medioambientales establece que están fuera de su ámbito de aplicación, entre otros, los daños y amenazas medioambientales provenientes de «a) un acto derivado de un conflicto armado, hostilidades, guerra civil o insurrección; b) un fenómeno natural de carácter excepcional, inevitable e irresistible» (Directiva 2004/35/CE, artículo 4).

Esta directiva ha sido, a su vez, transpuesta en España por la ley 26/2007 de Responsabilidad Medioambiental. Esta ley, en el marco de responsabilidad objetiva aplicable para las actividades de mayor riesgo potencial (descritas en su anexo iii), también contempla causas eximentes de responsabilidad que

incluyen determinados supuestos que son usuales en los regímenes de responsabilidad (fuerza mayor, actuación de un tercero ajeno al ámbito de la organización, cumplimiento de una orden o instrucción obligatoria dictada por una autoridad pública competente), o en las normas de protección ambiental comunitaria (actividades cuyo principal propósito sea servir a la defensa nacional o la seguridad internacional), así como la exclusión lógica de las actividades cuyo único propósito sea la protección contra los desastres naturales (Lozano, 2010, p. 399).

\section{III.2. Medidas de mitigación o remediación}

La Ley General del Ambiente establece, en el marco del principio de responsabilidad ambiental, establece que «el causante de la degradación del ambiente y de sus componentes, sea una persona natural o jurídica, pública o privada, está obligado a adoptar inexcusablemente las medidas

LAS CONDICIONES

EXIMENTES DE

RESPONSABILIDAD

ADMINISTRATIVA

EN ELTEXTO

ÚNICO ORDENADO

DE LA LEY DEL

PROCEDIMIENTO

ADMINISTRATIVO

GENERAL Y SU

INCIDENCIA EN

LA LEGISLACIÓN

AMBIENTAL

EXEMPTION

CONDITIONS OF

LIABILITY INTHE

LAW ON GENERAL

ADMINISTRATIVE

PROCEDURE

AND ITS

INCIDENCE INTHE

ENVIRONMENTAL

LEGISLATION 
para su restauración, rehabilitación o reparación según corresponda...» (ley 28611, Título Preliminar, artículo IX).

Por ello, como concepto general, el causante de un daño ambiental debe establecer medidas de mitigación ambiental, definiéndose estas como las «medidas o actividades orientadas a atenuar, minimizar o eliminar los impactos ambientales y sociales negativos que un proyecto puede generar sobre el ambiente» (Ministerio del Ambiente-MINAM, 2012, p. 87). A mayor abundamiento, la Ley General del Ambiente también tiene como mandato que los titulares de actividades productivas o extractivas realicen actividades preventivas ${ }^{3}$ en cuidado del medio ambiente. Asimismo, encontramos que la acción de mitigación ambiental ante los daños también sea exigible conforme a los instrumentos de gestión ambiental de la actividad en curso (Vera, 2015, p. 148), lo cual se puede apreciar en el siguiente gráfico:

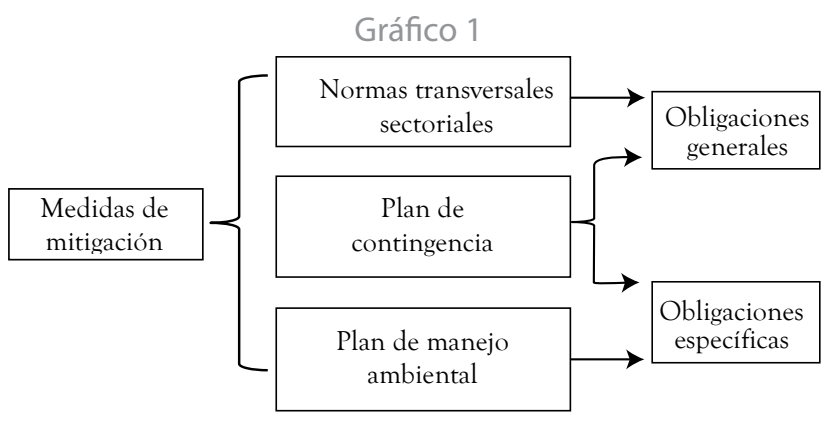

Fuente: Vera (2015, p. 142)

En ese sentido, es claro que el derecho administrativo ambiental tiene como objetivo primordial prevenir los daños ambientales. Y, si estos se llegan a producir, lo que corresponde es remediarlos, tratando de que las cosas vuelvan al estado anterior de la infracción.

Ahora bien, estas medidas de mitigación ambiental van cambiando de nombre conforme a la legislación que las va desarrollando. Por un lado, serán medidas complementarias, medidas administrativas y hasta se las conocerá como mediadas accesorias. Por otro lado, si no hay un procedimiento administrativo sancionador iniciado, se llamarán medidas preventivas, y si ya lo hay, se llamarán medidas correctivas. Esta situación, se explica en razón de que «estas medidas están calificadas por el propósito que persiguen y no por su contenido que hace a su

3 Un enunciado, directamente relacionado con este punto que establece, dentro del principio de prevención, que «la gestión ambiental tiene como objetivos prioritarios prevenir, vigilar y evitar la degradación ambiental. Cuando no sea posible eliminar las causas que la generan, se adoptan las medidas de mitigación, recuperación, restauración o eventual compensación, que correspondan» (ley 28611, Título Preliminar, artículo Vl). 
objeto». Es decir, la denominación que reciban dependerá del «contexto y finalidad perseguida por la autoridad» (Morón, 2010, p. 140).

Estas medidas de mitigación o medidas correctivas en sentido general, contrariamente a lo que podría pensarse, no son propias de la actividad sancionadora, sino de la actividad lógicamente anterior, esto es, de la supervisión. Es allí donde se emite la «orden administrativa», a saber, «una especie de acto administrativo de gravamen a través del cual se manifiesta el poder de policía ostentado por las autoridades administrativas para imponer una conducta determinada» (Morón, 2010, p. 141).

Una vez concluida la etapa de fiscalización, se inicia «la represión administrativa de los ilícitos ambientales, [donde] como en la generalidad del derecho administrativo sancionador, la medida sancionatoria más extendida es la sanción pecuniaria, seguidas en este ámbito de las sanciones rescisorias, que conllevan la clausura del establecimiento o el cese de la actividad que dio lugar a la conducta infractora» y, a su vez, se dictan medidas correctivas que buscan la «reposición de las cosas al estado anterior a la comisión de la infracción» (Lozano, 2010, p. 735).

Nótese que estas medidas correctivas no son una sanción, pues no tienen un contenido aflictivo, sino que buscan reparar el daño causado al ambiente. Si bien muchas veces son «accesorias» a la imposición de una sanción pecuniaria, cuando las circunstancias ambientales lo ameritan, pueden ser perfectamente autónomas. Es decir, «debe reiterarse de inmediato la autonomía de la sanción y la obligación de reparar» (Esteve Pardo, 2014, p. 50).

Como se puede apreciar, cuando estemos ante un procedimiento administrativo sancionador ambiental, por regla general, al infractor se le impondrá una sanción pecuniaria aparejada de una medida correctiva. Sin embargo, ¿qué sucede cuando en estas circunstancias opera un eximente de responsabilidad administrativa?

Si bien las causales de eximencia liberarán al administrado de la responsabilidad administrativa y la consiguiente sanción pecuniaria, no lo liberan de asumir las medidas de mitigación que debe realizar. En otras palabras, continúa obligado de realizar la restauración, rehabilitación o reparación ambiental a que hubiera lugar. Recuérdese que estas obligaciones nacen del principio de prevención, así como de los compromisos asumidos por los administrados en sus instrumentos de gestión ambiental y no del procedimiento administrativo sancionador.

Una circunstancia similar se produce cuando el administrado, operando dentro de los límites que la ley le otorga, produce un daño ambiental y, por tanto, debe realizar acciones de mitigación. Como se sabe, la Ley General del Ambiente establece que aún en el supuesto que el

LAS CONDICIONES EXIMENTES DE RESPONSABILIDAD ADMINISTRATIVA EN EL TEXTO ÚNICO ORDENADO DE LA LEY DEL PROCEDIMIENTO ADMINISTRATIVO GENERAL Y SU INCIDENCIA EN LA LEGISLACIÓN AMBIENTAL

EXEMPTION CONDITIONS OF LIABILITY INTHE LAW ON GENERAL ADMINISTRATIVE PROCEDURE

AND ITS

INCIDENCE IN THE ENVIRONMENTAL LEGISLATION 
administrado haya cumplido con la normatividad sobre la materia (es decir, no sea responsable administrativamente), subsiste la obligación legal de que asuma la remediación de los daños que generó con su actividad (Lanegra, 2013, p. 193). Asimismo, esta obligación legal tiene como correlato fáctico que «un mismo volumen de emisiones atmosféricas puede tener un efecto negativo mucho mayor si se da una persistente situación anticiclónica sin vientos que dispersen esta contaminación. Un mismo vertido en un río puede tener consecuencias nefastas en periodo de estiaje con muy bajo caudal o pasar del todo inadvertido cuando el río lleva un gran caudal del agua» (Esteve Pardo, 2014, p. 19).

Es decir, la relación entre elementos abióticos (agua, aire, suelo) y los elementos bióticos (microrganismos, flora, fauna) que conforman el ecosistema es muy compleja. Por eso, siempre le es exigible al administrado que mitigue los impactos ambientales negativos que ha generado en mérito a las obligaciones generales o específicas que le son propias por la labor riesgosa que desempeña.

\section{III.3. Persecución del daño y del riesgo}

El derecho ambiental ha sido definido como un derecho de gestión y regulación de riesgos, que se explica y encuentra sentido en la sociedad posmoderna, y que se ha dado en llamar sociedad de riesgo. Por ello, sus cometidos esenciales son dos: primero, decidir qué riesgos se admiten, y, segundo, gestionar estos riesgos. La actividad administrativa de inspección forma parte, entre otras, de dicha gestión de riesgos (Esteve Pardo, 2014, pp. 14ss.).

Por ello, la Administración no solo actuará cuando producto de una infracción se haya ocasionado un daño al ecosistema, sino también —la gran mayoría de veces - cuando se haya generado un riesgo ambiental. En atención a ello y como parte de la gestión del riesgo ambiental durante la actividad administrativa de fiscalización, el Reglamento de Supervisión del Organismo de Evaluación y Fiscalización Ambiental (OEFA) desarrolla una «Metodología para la estimación del riesgo ambiental que genera el incumplimiento de las obligaciones ambientales fiscalizables». Esta metodología es un importante esfuerzo para brindar parámetros objetivos de medición sobre las consecuencias de las conductas infractoras. Cabe destacar que su elaboración es el resultado de una abstracción de los casos más recurrentes que se presentan. Asimismo, toma como marco conceptual, entre otros, una norma técnica española y una guía del Ministerio del Ambiente.

La norma española, «Análisis y evaluación del riesgo ambiental» (UNE 150008:2008), señala que toda metodología debe incorporar la 
concatenación en el espacio-tiempo de las causas, por un lado, y de las consecuencias, por el otro, que derivan en un accidente concreto con un daño asociado. La norma precisa, además, que el elemento de conexión entre ambos escenarios son los sucesos iniciadores (Asociación Española de Normalización y Certificación-AENOR, 2008).

Por su parte, la Guía de evaluación de riesgo ambiental define el «árbol de fallas» como la «metodología deductiva para la detección de riesgos, se representa por un modelo grafico en forma de árbol invertido, que ilustra la combinación lógica de fallos parciales que conducen al fallo del sistema» (MINAM, 2009, p. 37). También define el «análisis de consecuencias» como el «método de evaluación que permite la cuantificación de la probabilidad de un accidente y el riesgo asociado al funcionamiento de una planta [industrial], se basan en la descripción gráfica de las secuencias del accidente» (2009, p. 37).

Así, ambos documentos establecen como fórmula general que el riesgo es igual a la probabilidad de que un evento se realice multiplicado por las consecuencias dañosas que ocasionaría. Esto puede expresarse en la siguiente fórmula, Riesgo $=$ Probabilidad $\mathrm{x}$ Consecuencia, $\mathrm{y}$ graficarse como sigue:

\section{Gráfico 2}

Estimador del riesgo ambiental

Consecuencia

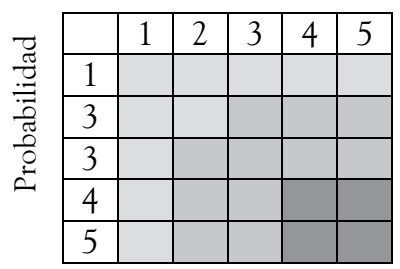

LAS CONDICIONES

EXIMENTES DE

RESPONSABILIDAD

ADMINISTRATIVA

EN ELTEXTO

ÚNICO ORDENADO

DE LA LEY DEL

PROCEDIMIENTO

ADMINISTRATIVO

GENERAL Y SU

INCIDENCIA EN

LA LEGISLACIÓN

AMBIENTAL

EXEMPTION

CONDITIONS OF

LIABILITY INTHE

LAW ON GENERAL

ADMINISTRATIVE

PROCEDURE

AND ITS

INCIDENCE IN THE

ENVIRONMENTAL

LEGISLATION

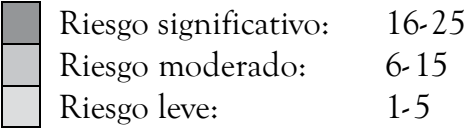

Fuente: Cuadro elaborado por el MINAM (2009, p. 32), sobra la base de la norma UNE 150008:2008 (AENOR, 2008).

De este modo, la Metodología para la estimación del riesgo ambiental, aprobada por el OEFA, establece que las conductas infractoras pueden generar un riesgo significativo (16-25 puntos), un riesgo moderado (6-15 puntos) o un riesgo leve (1-5 puntos). Para llegar a dicho resultado existen dos factores relevantes: 1) las consecuencias en el entorno humano y 2) las consecuencias en el entorno natural. A partir de estos factores es posible elaborar tablas donde se asigna valores a la cantidad de personas 
potencialmente expuestas y al entorno natural potencialmente afectado, así como a la cantidad del agente contaminante, su peligrosidad y la extensión del evento.

Lo importante es analizar el riesgo como un elemento constitutivo de la infracción y determinar con parámetros previamente establecidos cuán peligrosa es la conducta del infractor para el ambiente y la salud de las personas. Para observar cómo el Tribunal de Fiscalización Ambiental ha aplicado la metodología, en especial con relación a la estimación de la probabilidad de ocurrencia del suceso iniciador — definido como «la frecuencia con la que podría generarse el riesgo en función a la actividad que realiza el administrado» (numeral 2.2.1) - , pueden consultarse, entre otras, las siguientes resoluciones del Tribunal de Fiscalización Ambiental del OEFA: Resolución 015-2017-OEFA/TFA-SMEPIM (fundamentos 93ss.); Resolución 024-2017-OEFA/TFA-SMEPIM (fundamentos 107ss.); Resolución 027-2017-OEFA/TFA-SMEPIM (fundamentos 63ss.); Resolución 030-2017-OEFA/TFA-SMEPIM (fundamentos 92ss.); Resolución 036-2017-OEFA/TFA-SMEPIM (fundamentos 114ss.).

\section{III.4. Eximentes de responsabilidad}

Como se ha visto en los parágrafos precedentes, en derecho ambiental se ha establecido un sistema de responsabilidad objetiva relativa. En este sistema, la mitigación de los daños y la neutralización de los riesgos generados por los administrados tienen una especial importancia. Por lo tanto, son autónomas las medidas de mitigación que dicten. Bajo este marco, veremos en este artículo la subsanación voluntaria, así como el caso fortuito y la fuerza mayor que son los eximentes que invocan los administrados en materia ambiental — podría decirse, casi de manera exclusiva-.

Por otro lado, no tenemos conocimiento de que en el sector ambiental se hayan aplicado otras causales de eximencia del artículo 255 del TUO de la LPAG, como el error inducido por la administración; obrar en cumplimiento de un deber legal y legítima defensa; la incapacidad mental debidamente comprobada; o la orden obligatoria de autoridad competente ${ }^{4}$.

\section{III.4.1. Subsanación voluntaria}

Recordemos que la configuración de este eximente de responsabilidad administrativa se produce en dos momentos perfectamente diferenciados. En un primer momento, se dan los tres elementos de la responsabilidad

4 A manera de ilustración, debemos indicar que en Europa el «obrar en cumplimiento de un deber legal» es una modalidad de fuerza mayor y se cita como ejemplo cuando "un operador haya causado daños al llevar a cabo una actividad en cumplimiento de una orden ineludible emanada de una autoridad pública" (Comunidad Europea, 2000, p. 19). 
administrativa: tipicidad, antijuridicidad y culpabilidad, vulnerándose el funcionamiento global de un sector social administrativamente regulado. Sin embargo, en un segundo momento, al ser corregida la conducta y revertidos los daños producidos, antes de la imputación de cargos, el administrado acredita ante la administración que el sector social bajo su competencia se encuentra «nuevamente» funcionando, por lo que ya no es necesaria su intervención sancionadora.

En ese sentido, esta causal de eximencia administrativa es similar en su operatividad al principio de oportunidad aplicado en el ámbito penal a los delitos de gravedad reducida. Claro está, siempre y cuando se haya verificado el resarcimiento económico para la víctima o sociedad. Esto puede apreciarse en la sentencia emitida en el expediente número 060-2013-77-2901 sobre delito contra el medio ambiente en la modalidad culposa (Caro \& Reyna, 2015, p. 278).

Ahora bien, el artículo 11 de la Ley del SINEFA — modificado por la ley 30011 - establece que la función supervisora del OEFA tiene como objetivo adicional promover la «subsanación voluntaria» de los presuntos incumplimientos de las «obligaciones ambientales» antes de iniciado el procedimiento administrativo sancionador, precisando que, en estos casos, respecto de una «infracción subsanable», se podrá archivar la investigación correspondiente.

Si bien ya se encuentra derogado, durante sus tres años de vigencia, el «Reglamento para la subsanación voluntaria de incumplimientos de menor trascendencia» precisó que, si se estaba ante un «hallazgo de menor trascendencia», la subsanación voluntaria antes del inicio del procedimiento administrativo sancionador generaba que se concluya la investigación (artículo 6). Para otros casos de mayor gravedad, se indicó que la subsanación voluntaria antes del inicio del procedimiento sancionador era únicamente un factor atenuante en la graduación de la sanción a imponer.

Como se puede apreciar, varios años antes de que en el TUO de la LPAG se incorpore la subsanación voluntaria como causal eximente, la misma ya se encontraba regulada en la normatividad de la fiscalización ambiental. Ahora bien, la Ley del SINEFA no definió qué era una «infracción subsanable», dejando que dicho concepto sea evaluado caso por caso. Más aún, conforme al derogado reglamento sobre la materia, esta subsanación solo era aplicable, como eximente, a los «hallazgos de menor trascendencia».

Posteriormente, el artículo 255 (1.f) del TUO de la LPAG incorpora la subsanación voluntaria como eximente de responsabilidad administrativa, pero tampoco define qué debe entenderse por «subsanación». Por ello, muchos administrados alegarán que subsanar es 
igual a «cesar en la realización de la conducta», es decir, que se les debe aplicar el eximente al haber dejado de realizar la conducta infractora que se les imputaba, sin que sea necesario que reviertan los impactos negativos que han ocasionado. Sobre el particular, consideramos que una correcta interpretación de lo que se entiende por «subsanación» debe hacerse a la luz del artículo VI del Título Preliminar de la Ley General del Ambiente que, como ya hemos visto, dentro del principio de prevención establece como objetivos que se debe evitar la «degradación ambiental» y, cuando esta se produce, se deben adoptar las medidas de «mitigación, recuperación [y] restauración» que sean necesarias.

Por ello, la subsanación de la conducta está íntimamente ligada a las acciones de mitigación ambiental que realice el administrado. Además, conforme a lo señalado, habrá impactos ambientales que podrán ser mitigados y otros que no. Por ejemplo, si un administrado vierte aguas acidas en un cuerpo de agua, inmediatamente los contaminantes se diluyen y viajan cientos de kilómetros aguas abajo, impactando negativamente a los microorganismos, la flora y fauna que encuentran en su trayecto. Lo inmediato de la contaminación hace que sea imposible que el administrado subsane los efectos de su conducta. Es decir, podrá cesar la conducta, pero no podrá mitigar sus efectos.

Por otro lado, si bien el artículo 255 (1.f) del TUO de la LPAG tampoco ha definido qué debe entenderse por subsanación «voluntaria», esto es la espontaneidad de la subsanación, el artículo 15 del Reglamento de Supervisión del OEFA, recientemente modificado, ha señalado que la subsanación dejará de ser voluntaria cuando existan «requerimientos efectuados por la autoridad de supervisión». Esto es correcto pues, desde dicho requerimiento, la corrección de la conducta deja de ser por propia iniciativa del administrado.

Finalmente, la subsanación voluntaria contemplada en el TUO de la LPAG, concordada con la Ley del SINEFA y desarrollada por el Reglamento de Supervisión del OEFA, se refleja en la «Metodología para el cálculo de las multas base y la aplicación de los factores agravantes y atenuantes a utilizar en la graduación de sanciones». Esta metodología tiene por objetivo brindar mayores incentivos para que los infractores corrijan su conducta y reviertan los efectos negativos de la misma pues, bien entendido, el procedimiento administrativo sancionador no tiene como objetivo imponer sanciones, sino hacer que se cumpla con los mandatos y prohibiciones de la Administración. Es decir, se busca que el sector ambiental funcione adecuadamente, corrigiéndose las perturbaciones y haciendo que la cosas vuelvan al estado anterior de la infracción. 
Cabe destacar que, en un caso reciente, el Tribunal de Fiscalización Ambiental ha señalado que, en la medida en que conforme a los medios probatorios aportados el administrado había subsanado voluntariamente su conducta antes del inicio del procedimiento administrativo sancionador — esto es, había almacenado adecuadamente balones de gas y termas en desuso- , correspondía revocar la resolución apelada en aplicación de la subsanación voluntaria, contemplada como eximente de responsabilidad en el TUO de la LPAG (Resolución 008-2017OEFA/TFA-SME, fundamentos 41-42).

En tal sentido, la subsanación voluntaria de la infracción como causal de eximencia (contemplada en el literal f) del numeral 1) del artículo 255 del TUO de la LPAG) no contraría las normas del sector ambiental, pues dicha causal ya se encontraba configurada en el artículo 11 de la Ley del SINEFA y ha sido desarrollada por el Reglamento de Supervisión del OEFA y la Metodología para el cálculo de las multas base y la aplicación de los factores agravantes y atenuantes a utilizar en la graduación de sanciones.

\section{III.4.2. Caso fortuito y fuerza mayor}

El artículo 146 de la Ley General del Ambiente ha establecido el siguiente eximente, entre otros: «b) cuando el daño o el deterioro del medio ambiente tenga su causa exclusiva en un suceso inevitable o irresistible». En su momento, este mandato fue regulado por la ahora derogada sexta norma de las «Reglas Generales sobre el ejercicio de la Potestad Sancionadora del Organismo de Evaluación y Fiscalización Ambiental-OEFA». Dicha norma, durante su vigencia, precisaba que, si bien el artículo 18 de la Ley del SINEFA preceptúa que la responsabilidad administrativa en materia ambiental es objetiva, en aplicación del principio de presunción de licitud, el OEFA se encuentra obligado a acreditar la infracción administrativa (nexo causal). Por otro lado, facultaba al administrado a eximirse de responsabilidad administrativa si acreditaba la fractura del nexo causal sea por caso fortuito, fuerza mayor o hecho determinante de tercero.

En aplicación de dichas normas, el Tribunal de Fiscalización Ambiental señaló que el rompimiento de una tubería y consiguiente derrame de aguas ácidas hacia una quebrada, por una maniobra equivocada del operador, no constituye un caso fortuito, pues oportunamente debieron tomarse las medidas de prevención correspondientes (Resolución 020-2015-OEFA/TFA-SEM, fundamento 59). Como se puede apreciar, el hecho invocado por el administrado no tenía las características de irresistible ni imprevisible. Asimismo, en otro caso, el Tribunal de Fiscalización Ambiental señaló que el corte de energía eléctrica no es un hecho imprevisible e irresistible, toda vez que, luego de producido dicho evento, la administrada tuvo la oportunidad de actuar de tal forma que

LAS CONDICIONES EXIMENTES DE RESPONSABILIDAD ADMINISTRATIVA

EN EL TEXTO

ÚNICO ORDENADO

DE LA LEY DEL

PROCEDIMIENTO

ADMINISTRATIVO

GENERAL Y SU

INCIDENCIA EN

LA LEGISLACIÓN

AMBIENTAL

EXEMPTION

CONDITIONS OF

LIABILITY INTHE

LAW ON GENERAL

ADMINISTRATIVE

PROCEDURE

AND ITS

INCIDENCE IN THE ENVIRONMENTAL LEGISLATION 
el equipo que dejó de funcionar (espesador) no produzca un rebalse de relaves en el ambiente (Resolución 024-2016-OEFA/TFA-SME, fundamento 42).

Cabe destacar que para que se produzca el rompimiento del nexo causal, el caso fortuito o fuerza mayor debe ser la causa exclusiva del evento dañoso, toda vez que, si existe una causa concomitante imputable al administrado, sí habrá responsabilidad administrativa (Andaluz, 2013, p. 820). Por otro lado, si debido a la ocurrencia de un terremoto, se desprende un muro de la planta de tratamiento de relaves mineros y se contaminan el río y los pastizales de una comunidad campesina, si bien operará esta causal eximente en favor del administrado dentro de un procedimiento administrativo, por otro lado, en materia civil nace de manera automática en favor de los afectados el derecho a la indemnización por los daños sufridos (Vidal Ramos, 2014, p. 145). Asimismo, en este supuesto, si bien el administrado se libera de la sanción, igual sigue obligado a cumplir las medidas correctivas que le imponga la Administración para proteger el ecosistema.

En tal sentido, el caso fortuito y la fuerza mayor como causal de eximencia, regulada en el literal a) del numeral 1) del artículo 255 del TUO de la LPAG, no contraría las normas del sector ambiental, pues dicha causal ya encontraba configurada en el artículo 146 de la Ley General del Ambiente. Tan es así que, desde hace muchos años, en los procedimientos sancionadores tramitados ante el OEFA, los administrados han alegado esta causal de eximencia, la cual ha sido evaluada caso por caso.

\section{III.5. La carga de la prueba de los eximentes en materia ambiental}

Conforme al principio de verdad material, contemplado en el artículo IV del Título Preliminar del TUO de la LPAG, la autoridad administrativa está facultada para verificar la verdad de los hechos que le son propuestos por las partes, más aún en los casos en que está de por medio el interés público, sin que ello signifique que se sustituya en el deber probatorio que le corresponde a las partes. En ese sentido, corresponde al administrado probar existencia de las causales de eximencia y no corresponde a la Administración probar su inexistencia, lo cual ha sido reiterado en variada jurisprudencia.

Por ejemplo, en un caso, una empresa tenía como compromiso ambiental realizar la evaluación de plomo en la sangre de los trabajadores que laboraron en un depósito de concentrados mineros. La empresa alegó que había incumplido dicha obligación por hecho determinante de tercero, esto es, que sus extrabajadores se habían negado a brindar su 
consentimiento para que se les practique dicha prueba. El Tribunal de Fiscalización Ambiental señaló que la administrada debió tomar las acciones del caso para asegurar su cumplimiento y, de no ser posible, generar de manera oportuna medios probatorios que acrediten que se vio imposibilitada de cumplir con dicho compromiso ambiental. Esto no sucedió en el procedimiento iniciado, por lo que se confirmóla resolución de primera instancia que la halló responsable administrativamente (Resolución 039-2016-OEFA/TFA-SME, fundamento 87).

\section{CONCLUSIONES}

En el marco de la responsabilidad administrativa subjetiva contemplada en el TUO de la LPAG, se han introducido en el artículo 255 seis causales eximentes de responsabilidad administrativa: 1) la subsanación voluntaria; 2) el error inducido por la administración; 3) el caso fortuito y fuerza mayor; 4) obrar en cumplimiento de un deber legal y legítima defensa; 5) la incapacidad mental debidamente comprobada; y 6) la orden obligatoria de autoridad competente.

Los artículos 144 y 146 de la Ley General del Ambiente han establecido un régimen de responsabilidad objetiva relativa, pues han normado causales eximentes que permiten el rompimiento del nexo causal, tales como el caso fortuito, fuerza mayor y hecho determinante de tercero. Asimismo, el artículo 11 de la Ley del SINEFA también ha establecido como una causal eximente la subsanación voluntaria de la conducta infractora.

En tal sentido, las causales eximentes de responsabilidad subjetiva contempladas en el TUO de la LPAG son concordantes con las causales eximentes de responsabilidad objetiva reguladas en la Ley General del Ambiente y en la Ley del SINEFA. En ambos sistemas corresponde que el administrado acredite el rompimiento del nexo causal a fin de que no se le aplique la sanción pecuniaria correspondiente. Sin embargo, con independencia de que operen o no las causales eximentes de responsabilidad, conforme a la Ley General del Ambiente y a la Ley del SINEFA, el administrado siempre se encuentra obligado a implementar las medidas de mitigación (preventivas o correctivas) que le ordene la Administración para remediar, reparar o rehabilitar los daños ambientales generados por su actividad, así como para neutralizar los riesgos que hubiera generado.

En el derecho administrativo sancionador peruano, está en proceso de construcción y desarrollo el marco conceptual de los eximentes de responsabilidad, en especial con respecto a sus formas de aplicación en cada sector social regulado. Sin perjuicio de ello, se han recibido importantes aportes del Tribunal Constitucional sobre el cumplimiento

LAS CONDICIONES EXIMENTES DE RESPONSABILIDAD ADMINISTRATIVA

EN EL TEXTO ÚNICO ORDENADO DE LA LEY DEL PROCEDIMIENTO ADMINISTRATIVO GENERAL Y SU INCIDENCIA EN LA LEGISLACIÓN AMBIENTAL

EXEMPTION CONDITIONS OF LIABILITY INTHE LAW ON GENERAL ADMINISTRATIVE PROCEDURE

AND ITS

INCIDENCE IN THE ENVIRONMENTAL LEGISLATION 
de órdenes obligatorias, así como del Poder Judicial sobre la subsanación voluntaria. Por su parte, el Tribunal de Fiscalización Ambiental se viene pronunciando sobre la subsanación voluntaria así como sobre el caso fortuito y fuerza mayor, que son las circunstancias eximentes que invocan los administrados en los procedimientos recursivos.

\section{REFERENCIAS}

Andaluz, C. (2013). Manual de derecho ambiental. Lima: Iustitia.

Baca, V. (2010). ¿Responsabilidad subjetiva u objetiva en materia sancionadora? Una propuesta de respuesta a partir del ordenamiento peruano. Texto de la ponencia presentada en el IV Congreso Internacional de Derecho Administrativo, realizado en Mendoza, Argentina. Recuperado de http://www.mpfn.gob.pe/escuela/ contenido/actividades/docs/2271_responsabilidad_subjetiva_u_objetiva_en_ materia_sancionadora.pdf

Caro, C. \& Reyna, M. (2015). Defensa penal de la empresa y sus funcionarios en delitos ambientales. Lima: Jurista Editores.

Comunidad Europea (2000). Libro Blanco sobre responsabilidad ambiental. Luxemburgo: Comisión. Recuperado de http://ec.europa.eu/environment/legal/ liability/pdf/el_full_es.pdf

DelaPuente, L. \& Vargas, V. (2015). Análisiscríticodel régimen de responsabilidad de la Ley General del Ambiente. Círculo de Derecho Administrativo, 15, 97-113. Recuperado de http://revistas.pucp.edu.pe/index.php/derechoadministrativo/ article/view/15172/15662

Esteve Pardo, J. (2014). Derecho del medio ambiente. Madrid: Ediciones Jurídicas y Sociales.

García Cavero, P. (2012). Derecho penal: parte general. Lima: Juristas Editores.

Gómez, M. \& Sanz, I. (2010). Derecho administrativo sancionador. Navarra: Aranzadi.

Lanegra, I. (2013). El daño ambiental en la Ley General del Ambiente. Derecho PUCP, 70, 187-196. Recuperado de http://revistas.pucp.edu.pe/index.php/ derechopucp/article/view/6750

Lozano, B. (2010). Derecho administrativo sancionador. Madrid: LA LEY.

Ministerio de Justicia (MINJUS) (2017). Guía práctica sobre el procedimiento administrativo sancionador: actualizada con el Texto Único Ordenado de la Ley $N^{\circ}$ 27444, Ley del Procedimiento Administrativo General. Guía para asesores jurídicos del Estado (2da ed.). Lima: Autor. Recuperado de https://www.minjus.gob.pe/wpcontent/uploads/2017/07/MINJUS-DGDOJ-GUIA-DE-PROCEDIMIENTOADMINISTRATIVO-SANCIONADOR-2DA-EDICION.pdf

Ministerio del Ambiente (MINAM) (2009). Guía de evaluación de riesgo ambiental. Lima: Autor. Recuperado de http:/bibliotecavirtual.minam.gob.pe/ biam/bitstream/id/853/BIV00306.pdf 
Ministerio del Ambiente (MINAM) (2012). Glosario de términos para la gestión ambiental peruana. Lima: Autor.

Morón, J. (2010). Los actos-medidas (medidas correctivas, provisionales y de seguridad) y la potestad sancionadora de la Administración. Círculo de Derecho Administrativo, 9, 135-157. Recuperado de http://revistas.pucp.edu.pe/index.php/ derechoadministrativo/article/view/13710/14334

Morón, J. (2014). Comentarios a la Ley del Procedimiento Administrativo General. Lima: Gaceta Jurídica.

Nieto, A. (2012). Derecho administrativo sancionador. Madrid: Tecnos.

Rebollo Puig, M. et al. (2010). Derecho administrativo sancionador. Madrid: LEX NOVA.

Rodríguez Hurtado, M.P., Ugaz Zegarra, A.F., Gamero Calero, L.M \& Schönbohm, H. (2012). Manual de casos penales: La teoría general del delito y su importancia en el marco de la reforma procesal penal. Lima: AMBERO ConsultingCooperación Alemana al Desarrollo Internacional (GIZ).

Vera, J. (2015). La mitigación ambiental en las actividades productivas o extractivas: concepto, obligatoriedad y aplicación práctica. Círculo de Derecho Administrativo, 15, 129-148. Recuperado de http://revistas.pucp.edu.pe/index. php/derechoadministrativo/article/view/15174

Vidal Ramos, R. (2014). La responsabilidad civil por daño ambiental en el sistema peruano. Lima: Lex \& Iuris.

\section{Jurisprudencia, normativa y otros documentos legales}

Asociación Española de Normalización y Certificación (AENOR) (2008). UNE 150008:2008, Análisis y evaluación del riesgo ambiental.

Corte Suprema de Justicia de la República [Perú], Acuerdo Plenario N²-2009/ CJ-116 (V Pleno Jurisdiccional de las Salas Penales Permanente y Transitorias, 13 de noviembre de 2009).

Decretolegislativo 1029, Decretolegislativo que modificala Ley del Procedimiento Administrativo General - ley 27444 y la Ley del Silencio Administrativo - ley 29060, Diario Oficial El Peruano, 24 de junio de 2008, 374615-374617.

Decreto legislativo 1272, Decreto legislativo que modifica la ley 27444, Ley del Procedimiento Administrativo General y deroga la ley 29060, Ley del Silencio Administrativo, Diario Oficial El Peruano, 21 de diciembre de 2016, Separata Especial, 607125-607145.

Decreto supremo 006-2017-JUS, Decreto supremo que aprueba el Texto Único Ordenado de la ley 27444 - Ley del Procedimiento Administrativo General, Diario Oficial El Peruano, 20 de marzo de 2017, 10-52.

Decreto supremo 023-2011-PCM, Decreto supremo que aprueba el Reglamento de la ley 29622, denominado «Reglamento de infracciones y sanciones para la responsabilidad administrativa funcional derivada de los informes emitidos por 
los órganos del Sistema Nacional de Control», Diario Oficial El Peruano, 18 de marzo de 2011, 439116-439131.

Directiva 010-2016-CG/GPROD, Procedimiento Administrativo Sancionador por Responsabilidad Administrativa Funcional, Resolución de Contraloría 129. 2016-CG, Diario Oficial El Peruano, 10 de mayo de 2016, 586668-586686.

Directiva 2004/35/CE del Parlamento Europeo y del Consejo, de 21 de abril de 2004, sobre responsabilidad medioambiental en relación con la prevención y reparación de daños medioambientales, Diario Oficial de la Unión Europea, L 143, $56-75$.

Efraín Raúl Chambilla Figueroa c. Director General de Personal de la PNP [acción de amparo], expediente 02446-2003-AA/TC, sentencia (Tribunal Constitucional [Perú], 30 de setiembre de 2005).

Ley 26/2007, de 23 de octubre, de Responsabilidad Medioambiental, Boletín Oficial del Estado (BOE), 255, 24 de octubre de 2007, 43229-43250.

Ley 27444, Ley del Procedimiento Administrativo General, Diario Oficial El Peruano, 11 de abril de 2001, 201208-201238.

Ley 28611, Ley General del Ambiente, Diario Oficial El Peruano, 15 de octubre de 2005, 302291-302310.

Ley 29325, Ley del Sistema Nacional de Evaluación y Fiscalización Ambiental, Diario Oficial El Peruano, 05 de marzo de 2009, 391802-391806.

Ley 30011, Ley que modifica la ley 29325, Ley del Sistema Nacional de Evaluación y Fiscalización Ambiental, Diario Oficial El Peruano, 26 de abril de 2013, 493631. 493634.

Metodología para el cálculo de las multas base y la aplicación de los factores agravantes y atenuantes a utilizar en la graduación de sanciones, aprobada por resolución 035-2013-OEFA/PCD y modificada por resolución 024-2017-OEFA/ CD. Recuperado de http://www.oefa.gob.pe/productos/metodologia-parael-calculo-de-las-multas-base-y-la-aplicacion-de-los-factores-agravantes-yatenuantes-a-utilizar-en-la-graduacion-de-sanciones

Reglamento de Supervisión del Organismo de Evaluación y Fiscalización Ambiental (OEFA), aprobado por resolución 005-2017-OEFA/CD y modificado por resolución 018-2017-OEFA/CD. Recuperado de http://www.oefa.gob.pe/ avisos/reglamento-de-supervision

Reglamento para la subsanación voluntaria de incumplimientos de menor trascendencia, aprobado por resolución 046-2013-OEFA-CD y derogado por el Reglamento de Supervisión del OEFA.

Reglas generales sobre el ejercicio de la potestad sancionadora del Organismo de Evaluación y Fiscalización Ambiental (OEFA), aprobadas por resolución 038-2013-OEFA-CD y derogadas por el Reglamento del Procedimiento Administrativo Sancionador (resolución 027-2017-OEFA-CD). 
Resolución 004-2013-CG/TSRA, Recurso de apelación interpuesto por Jorge David Salomón Reyes contra la Resolución N 002-002-2013-CG/SAN que impuso sanción de cinco años de inhabilitación para el ejercicio de la función pública (Tribunal Superior de Responsabilidades Administrativas, Contraloría General de la República [Perú], 02 de julio de 2013).

Resolución 008-2017-OEFA/TFA-SME, Empresa de Generación Huanza S.A. (Tribunal de Fiscalización Ambiental, Sala Especializada en Minería y Energía, 13 de enero de 2017).

Resolución 015-2017-OEFA/TFA-SMEPIM, Enel Generación Perú S.A.A. (antes, EDEGELS.A.A.) (Tribunal de Fiscalización Ambiental, Sala Especializada en Minería, Energía, Pesquería e Industria Manufacturera, 08 de junio de 2017).

Resolución 020-2015-OEFA/TFA-SEM, Minera Yanacocha S.R.L. (Tribunal de Fiscalización Ambiental, Sala Especializada en Minería, 24 de marzo de 2015).

Resolución 024-2016-OEFA/TFA-SME, Trevali Perú S.A.C. (Tribunal de Fiscalización Ambiental, Sala Especializada en Minería y Energía, 04 de noviembre de 2016).

Resolución 024-2017-OEFA/TFA-SMEPIM Pluspetrol Norte S.A. (Tribunal de Fiscalización Ambiental, Sala Especializada en Minería, Energía, Pesquería e Industria Manufacturera, 17 de julio de 2017).

Resolución 027-2014-CG/TSRA, Se declaran fundados en parte los Recursos de Apelación acumulados contra la Resolución $\mathrm{N}^{\circ}$ 001-004-2014-CG/SAN que impuso a los administrados sanción de suspensión temporal para el ejercicio de la función pública (Tribunal Superior de Responsabilidades Administrativas, Contraloría General de la República [Perú], 12 de agosto de 2014).

Resolución 027-2017-OEFA/TFA-SMEPIM, Petróleos del Perú-Petroperú S.A. (Tribunal de Fiscalización Ambiental, Sala Especializada en Minería, Energía, Pesquería e Industria Manufacturera, 25 de julio de 2017).

Resolución 030-2017-OEFA/TFA-SMEPIM, Pluspetrol Norte S.A. (Tribunal de Fiscalización Ambiental, Sala Especializada en Minería, Energía, Pesquería e Industria Manufacturera, 15 de agosto de 2017).

Resolución 036-2017-OEFA/TFA-SMEPIM, Compañía Minera Barbastro S.A.C. (Tribunal de Fiscalización Ambiental, Sala Especializada en Minería, Energía, Pesquería e Industria Manufacturera, 31 de agosto de 2017).

Resolución 039-2016-OEFA/TFA-SME, Perubar S.A. (Tribunal de Fiscalización Ambiental, Sala Especializada en Minería y Energía, 25 de noviembre de 2016).

Resolución de Consejo Directivo 005-2017-OEFA/CD, Reglamento de Supervisión (OEFA), Diario Oficial El Peruano, 03 de febrero de 2017, Separata Especial, 1-16.

Resolución de Consejo Directivo 018-2017-OEFA/CD, Incorporan los artículos $22^{\circ}$ al $31^{\circ}$ que formarán parte del Título IV «De las Medidas Administrativas» y la Cuarta Disposición Complementaria Final en el Reglamento de Supervisión, 
aprobado por Resolución de Consejo Directivo 005-2017-OEFA/CD, Diario Oficial El Peruano, 09 de junio de 2017, 29-32.

Resolución de Consejo Directivo 024-2017-OEFA/CD, Modifican la res. Nº352013-OEFA/PCD, que aprueba metodología para el cálculo de multas base y la aplicación de factores agravantes y atenuantes a utilizarse en la graduación de sanciones, Diario Oficial El Peruano, 13 de setiembre de 2017, 36-38.

Resolución de Consejo Directivo 027-2017-OEFA-CD, Aprueban el Reglamento del Procedimiento Administrativo Sancionador del Organismo de Evaluación y Fiscalización Ambiental-OEFA, Diario Oficial El Peruano, 12 de octubre de 2017, 26-31.

Resolución de Consejo Directivo 038-2013-OEFA-CD, Aprueban las «Reglas Generales sobre el ejercicio de la Potestad Sancionadora del Organismo de Evaluación y Fiscalización Ambiental-OEFA», Diario Oficial El Peruano, 18 de setiembre de 2013, 503174-503176.

Resolución de Consejo Directivo 046-2013-OEFA/CD, Aprueban Reglamento para la subsanación voluntaria de incumplimientos de menor trascendencia, Diario Oficial El Peruano, 28 de noviembre de 2013, 507881-507883.

Resolución de Consejo Directivo 056-2017-CD/OSIPTEL, Modifican el Reglamento de Fiscalización, Infracciones y Sanciones del OSIPTEL, Diario Oficial El Peruano, 20 de abril de 2017, 52-55.

Resolución de Presidencia del Consejo Directivo 035-2013-OEFA/PCD y Anexos, Metodología para el cálculo de las multas base y la aplicación de los factores agravantes y atenuantes a utilizar en la graduación de sanciones, de acuerdo lo establecido en el artículo 6 del decreto supremo 007-2012-MINAM, Diario Oficial El Peruano, 12 de marzo de 2013, Separata Especial, 490584-490602.

Texto Único Ordenado de la Ley 27444, Ley del Procedimiento Administrativo General (1ra ed., junio 2017). Recuperado de http://spij.minjus.gob.pe/content/ publicaciones_oficiales/img/texto-unico.pdf 